
\title{
R Research Soure \\ Modeling And Optimization Study of PEMFC Fueled With Ammonia Reforming Gas
}

Jian Feng Zhao ( $\square$ jianfeng62300_zhao@163.com )

Naval University of Engineering https://orcid.org/0000-0002-3695-6480

LIANG Qianchao

Naval University of Engineering

LIANG Yifan

Naval University of Engineering

Original article

Keywords: ammonia reforming gas, PEMFC, anode channel, power density

Posted Date: July 26th, 2021

DOI: https://doi.org/10.21203/rs.3.rs-685498/v1

License: (1) This work is licensed under a Creative Commons Attribution 4.0 International License.

Read Full License 


\title{
Modeling and optimization study of PEMFC
}

\section{fueled with ammonia reforming gas}

\author{
ZHAO Jianfeng ${ }^{1 *}$, LIANG Qianchao ${ }^{1}$, LIANG Yifan ${ }^{1}$ \\ 1. College of Power Engineering, Naval University of Engineering, Wuhan 430033, China; \\ * Correspondence: jianfeng62300_zhao@163.com
}

Abstract: The storage of high-purity hydrogen has been a technical challenge limiting the large-scale application of fuel cells. Ammonia is an ideal hydrogen storage carrier with a storage mass density of up to $17 \mathrm{wt} \%$ and can be easily liquefied for storage and transportation, but ammonia requires complex separation equipment to re-generate high-purity hydrogen, which greatly reduces its advantages in hydrogen storage. Therefore, the development of direct ammonia reforming gas fuel cells, which can avoid complicated pure hydrogen separation equipment, has a very meaningful impact and can greatly expand the application of fuel cells.

In this paper, we study the modeling simulation of ammonia reforming gas-fueled proton exchange membrane fuel cell (PEMFC) based on the preliminary experiments, and the concentration-dependent Butler-Volmer electrochemical model is used to simulate the ammonia reforming gas-fueled PEMFC. Firstly, the concentration-dependent Butler-Volmer electrochemical model was improved by adding a correction factor for the concentration difference polarization based on the characteristics of the experimental data to obtain a correction factor of 1.65 based on the experimental data; secondly, the effect of the anode channel length on the fuel cell performance was investigated.

The results show that: firstly, the improved concentration-dependent Butler-Volmer electrochemical model can better match the experimental results; secondly, the anode channel length has less effect on the maximum power density and hydrogen concentration in the exhaust gas, and the current density gradient increases with decreasing anode channel length, but the fuel flow resistance decreases. The results of the study can provide a reference for the simulation study of PEMFC using ammonia reforming gas as fuel.

Keywords: ammonia reforming gas, PEMFC, anode channel, power density

\section{Introduction}

Proton exchange membrane fuel cells (PEMFC) have gained initial commercial applications in recent years [1]. Currently, PEMFCs are still fueled by high-purity hydrogen, which is expensive to produce and has a low storage volume energy density, so the large-scale application of PEMFC is still limited [2,3]. In contrast, ammonia as a chemical storage carrier for hydrogen has the advantages of high hydrogen storage density and easy storage, but it yields a nitrogen-hydrogen mixture(crude hydrogen) during reforming. The conventional method of hydrogen production from ammonia is to obtain high purity hydrogen by separation of crude hydrogen by pressure swing 
adsorption, composite metal palladium membrane separation and other methods [4-6]. However, for small portable PEMFC on-site hydrogen production units, the above methods still suffer from the problem of oversized units. Therefore, the development of PEMFC using ammonia reforming gas directly is very meaningful and can greatly expand the application of PEMFC.

Hunter et al. established an ammonia-reforming gas-PEMFC demonstration platform to demonstrate the feasibility of PEMFC using ammonia reforming gas directly [7]. Meanwhile, there have been numerous studies for the efficient decomposition of ammonia [8,9], but there are few studies on the effect of high nitrogen concentration on PEMFC. Previous studies have shown that nitrogen affects the diffusion and transport of hydrogen in the flow channel, but when pure hydrogen is used as fuel, its final accumulation is not high as it is regularly discharged regularly with anode purging. Therefore, for a PEMFC using pure hydrogen as fuel, the main purpose of flow channel geometry optimization is to optimize water management, thermal management and material distribution inside the cell [10-12]. However, for ammonia reforming gas, experiments have shown that due to the high initial concentration of nitrogen, the anode purging strategy cannot guarantee the proper operation of the fuel cell, so only the fuel flow control strategy can be used. Moreover, the nitrogen is increasingly concentrated in the fuel cell along the flow direction, and the rate of concentration increase is mainly determined by the flow rate of the gas in the flow channel and the consumption rate of hydrogen, so the influence of the geometry of the fuel cell anode flow channel of the fuel cell must be further studied and analyzed.

In this paper, a two-dimensional PEMFC model was established, and the concentration-dependent electrochemical mathematical model was reasonably modified based on the experimental data. Next, the effects of the flow length on the maximum power density, exhaust hydrogen concentration, current density and resistance loss of the fuel cell were studied.

\section{Mathematical modeling}

Since the anode and cathode channel of the PEMFC used in the experiment are perpendicular to each other, the air and fuel flow directions are cross-flowing, and the air composition on the cathode side corresponding to different anode channel will change along the air flow direction. Therefore, the modeling location in this paper is chosen to be in the mid-profile of the first anode channel at the air inlet [13]. To simplify the model, the air composition at the outer surface of the cathode diffusion layer is assumed to be the same as at the air inlet [14].The model contains six domains: anode channel, anode gas diffusion layer (an_GDL), anode catalyst layer(an_CL), proton exchange membrane(PEM), cathode catalyst layer(ca_CL), and cathode gas diffusion layer(ca_GDL) as shown in Figure 1. In order to further simplify the model, the following assumptions are adopted in this paper[15-19]:

(1) Each gas is regarded as an ideal gas.

(2) The generated water can quickly flow out with air in a gaseous form, and there is 
no liquid water in the cathode.

(3) The temperature distribution in PEMFC is uniform and constant.

(4) The penetration of water and nitrogen from the cathode side to the anode side is ignored.

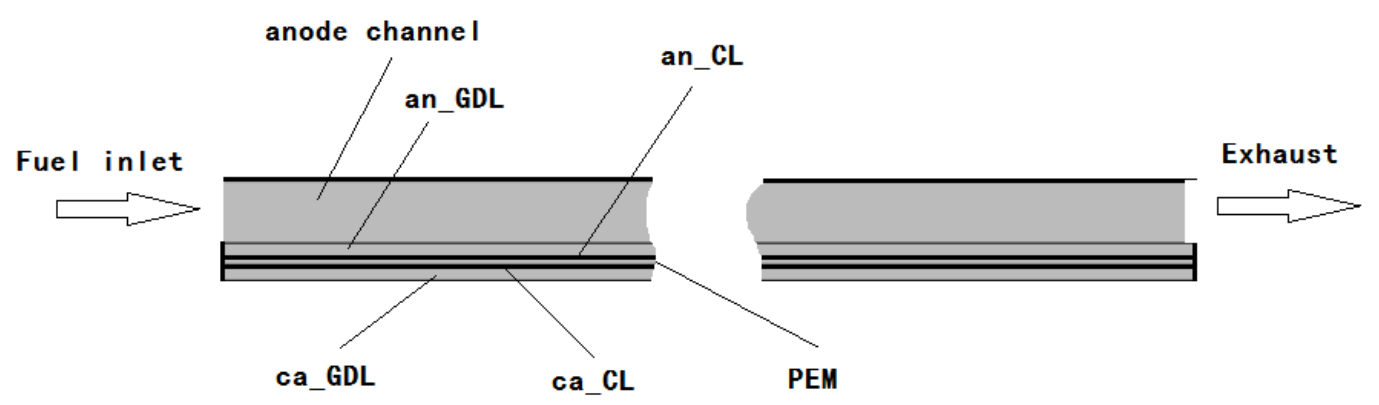

Fig.1 two-dimensional section of the modeling area

\subsection{Electrochemical model}

The cell voltage $V$ is described as follows:

$$
V=E_{0}-\eta_{\text {act }}-\eta_{\text {ohm }}
$$

Where $E_{0}$ is the theoretical reversible voltage which can be calculated from the Nernst equation[13]:

$$
E_{0}=1.229-0.85 * 10^{-3} *(T-298.15)+4.3085 * 10^{-5} * T *\left[\ln \left(P_{\mathrm{H}_{2}}^{*}\right)+0.5 * \ln \left(P_{\mathrm{O}_{2}}^{*}\right)\right]
$$

Anode local current density $i_{a}$ (Concentration-dependent Butler-Volmer equation)

$$
i_{a}=i_{0, a} *\left(e^{\left(-\frac{c_{H_{2}}}{c_{H_{2, r e f}}}\right)} * \exp \left(\frac{\alpha_{a, a} F \eta_{a}}{R T}\right)-\exp \left(\frac{-\alpha_{c, a} F \eta_{a}}{R T}\right)\right)
$$

Cathode local current density $i_{c}$ (Butler-Volmer equation)

$$
i_{c}=-i_{0, c}\left(\frac{c_{\mathrm{O}_{2}}}{c_{O_{2, r f}}}\right)\left(\exp \left(\frac{\alpha_{c, a} F \eta_{c}}{R T}\right)-\exp \left(\frac{-\alpha_{c, c} F \eta_{c}}{R T}\right)\right)
$$

$F$ is the Faraday's constant ( $\mathrm{SI}$ unit: $\mathrm{C} \mathrm{mol}^{-1}$ ), $c_{i, r e f}$ is the material reference concentration (SI unit: $\mathrm{mol} \mathrm{m} \mathrm{m}^{-3}$ ), $i_{0, a}$ and $i_{0, c}$ is the standard exchange current density (SI unit: $\left.\mathrm{A} \mathrm{m} \mathrm{m}^{-2}\right), R$ is the gas constant, $T$ is the temperature (SI unit: $\mathrm{K}$ ), $\alpha_{a, a}$, $\alpha_{a, c}, \alpha_{c, a}, \alpha_{c, c}$ is the transfer coefficient.

Anode over-potential $\eta_{a}$, cathode over-potential $\eta_{c}$ and total over-potential $\eta_{a c t}$ are given by the following equation: 


$$
\begin{gathered}
\eta_{a}=\phi_{s}-\phi_{l}-E_{e q, a} \\
\eta_{c}=\phi_{s}-\phi_{l}-E_{e q, c} \\
\eta_{a c t}=\eta_{a}+\eta_{c}
\end{gathered}
$$

Where $E_{\text {eq,i }}\left(\mathrm{SI}\right.$ unit: V) represents the equilibrium voltage, $\varphi_{\mathrm{s}}$ is the electronic potential (IS unit: V), and $\varphi_{1}$ is the ionic potential (IS unit: V).

Ohmic overpotentia $\eta_{o h m}$ :

$$
i_{e}=\sigma_{e} * \eta_{\text {ohm }, e}
$$

Where $\sigma_{e}$ (IS unit: $\mathrm{S} \mathrm{m}^{-1}$ ) is the electrical conductivity (where the index $e$ stands for "a"(anode) or "c"(cathode)).

\subsection{Momentum conservation equation}

Navier-Stokes equation and Brinkman equation are adopted to describe the flow in the free zone (anode channel) and porous zone, respectively. [20] The combination of Navier-Stokes equations and continuity equations can be expressed as:

$$
\begin{gathered}
(\rho u \cdot \nabla) u=-\nabla P+\nabla \cdot\left[\mu\left(\nabla u+(\nabla u)^{T}\right)-\frac{2}{3} \mu(\nabla \cdot u) I\right] \\
\nabla \cdot(\rho u)=0
\end{gathered}
$$

Where $\rho$ is the mixture density of the gas phase(SI unit: $\mathrm{kg} \mathrm{m}^{-3}$ ), $I$ is Unit Matrix, $P$ is the pressure(SI unit: $\mathrm{Pa}$ ), $\mu$ represents the gas viscosity(SI unit: $\mathrm{Pa} \mathrm{s}$ ), u is the velocity. The combination of Brinkman equation and continuity equation can be expressed as:

$$
\frac{\mu}{k} u=-\nabla p+\nabla \cdot \frac{1}{\varepsilon}\left[\mu\left(\nabla u+(\nabla u)^{T}\right)-\frac{2}{3} \mu(\nabla \cdot u) I\right]
$$

Where $k$ is permeability(IS unit: $\mathrm{m}^{2}$ ), $\varepsilon$ is porosity.

\subsection{Mass conservation equation}

The model takes into account two species in the anode $\left(\mathrm{H}_{2}\right.$ and $\left.\mathrm{N}_{2}\right)$ and three species at 
the cathode $\left(\mathrm{O}_{2}, \mathrm{H}_{2} \mathrm{O}\right.$ and $\left.\mathrm{N}_{2}\right)$, and uses Maxwell-Stefan multicomponent diffusion, governed by the following equations[20]:

$$
\nabla j_{i}+\rho(u \cdot \nabla) w_{i}=R_{i}
$$

Where $w_{i}$ is mass fraction of species $\mathrm{i}, R_{i}$ is chemical reaction rate of species $\mathrm{i}$ (IS unit: $\left.\mathrm{kg} \mathrm{m}^{-3} \mathrm{~s}^{-1}\right), j_{i}$ is the diffusion mass flow density of species $i$, which is defined as follows:

$$
\begin{gathered}
j_{i}=-\left(\rho D_{i}^{m} \nabla w_{i}+\rho w_{i} D_{i}^{m} \frac{\nabla M_{n}}{M_{n}}-j_{c, i}\right) \\
D_{i}^{m}=\frac{1-w_{i}}{\sum_{k \neq l} \frac{x_{k}}{D_{i k}}} \\
M_{n}=\left(\sum_{i} \frac{w_{i}}{M_{i}}\right)^{-1} \\
j_{c, i}=\rho w_{i} \sum_{i} \frac{M_{i}}{M_{n}} D_{k}^{m} \nabla x_{k}
\end{gathered}
$$

Here $x_{k}$ is mole fraction, $M_{i}$ is Molecular mass, $\quad D_{i}^{m}$ is the equivalent diffusion coefficient of species i in multicomponent, $D_{i k}$ is binary diffusion coefficient, which can be calculated by Fuller's empirical formula [21]:

$$
D_{i k}=3.198 * 10^{-8} * \frac{T^{1.75}}{P\left(v_{i}^{\frac{1}{3}}+v_{k}^{\frac{1}{3}}\right)^{2}}\left(\frac{1}{M_{i}}+\frac{1}{M_{k}}\right)^{0.5}
$$

Where $v_{i}$ is the molar diffusion volume of gas (IS unit: $\mathrm{cm}^{3} \mathrm{~mol}^{-1}$ ).

The binary diffusion coefficient obtained by Equation (20) needs to be modified in the porous region:

$$
D_{i k_{-} e f f}=\frac{\varepsilon}{\tau} D_{i k}
$$

Here $\tau$ is the tortuosity factor.

\subsection{Initial and boundary conditions of the fuel cell model}

The potential difference between the cathode and anode current collectors corresponds to the total cell voltage. Choose the potential at the upper surface of 
an_GDL as the reference level by setting it to zero. Then the total cell voltage serves as the boundary condition at the lower surface of ca_GDL:

$$
\begin{aligned}
& \phi_{s}=0 \text { at the upper surface of an_GDL } \\
& \phi_{s}=\mathrm{V} \text { at the lower surface of ca_GDL }
\end{aligned}
$$

The molar fraction of nitrogen at the anode inlet of the fuel cell is 0.25 and the molar fraction of hydrogen is 0.75 .

\section{Results and Discussion}

\subsection{Verification of simulation model}

Table 1 Geometric parameters, characteristic parameters and

\begin{tabular}{|c|c|c|}
\hline Parameters & Value & Ref. \\
\hline Anode channel length, $L(\mathrm{~mm})$ & 180 & measure data \\
\hline Anode runner height, $H(\mathrm{~mm})$ & 1 & measure data \\
\hline Anode gas diffusion layer thickness, $\sigma_{a d}(\mathrm{~mm})$ & 0.29 & [16] \\
\hline Cathode gas diffusion layer thickness, $\sigma_{c d}(\mathrm{~mm})$ & 0.254 & [16] \\
\hline Anode catalyst layer thickness, $\sigma_{a c}(\mathrm{~mm})$ & 0.0165 & [16] \\
\hline Cathode catalyst layer thickness, $\sigma_{c c}(\mathrm{~mm})$ & 0.0165 & [16] \\
\hline PEM thickness, $\sigma_{m}(\mathrm{~mm})$ & 0.0508 & [16] \\
\hline Electrical conductivity, $\sigma_{s}\left(\mathrm{~S} \mathrm{~m}^{-1}\right)$ & 220 & [22] \\
\hline Ionic conductivity, $\sigma_{l}\left(\mathrm{~S} \mathrm{~m}^{-1}\right)$ & 4.0 & $\begin{array}{l}{[22] \text { and }} \\
\text { Optimization }\end{array}$ \\
\hline $\begin{array}{l}\text { Permeability inside an_GDL and ca_GDL } \\
\text { domains, } \kappa_{d g l}\left(\mathrm{~m}^{2}\right)\end{array}$ & $1.18 \times 10^{-11}$ & [22] \\
\hline $\begin{array}{l}\text { Permeability inside an_CL and ca_CL domains, } \\
\kappa_{c l}\left(\mathrm{~m}^{2}\right)\end{array}$ & $2.36 \times 10^{-12}$ & [22] \\
\hline $\begin{array}{l}\text { Porosity inside an_GDL and ca_GDL domains, } \\
\varepsilon_{d g l}\end{array}$ & 0.4 & [22] \\
\hline Porosity inside an_CL and ca_CL domains, $\varepsilon_{c l}$ & 0.3 & [22] \\
\hline Gas viscosity inside anode domains, $\mu_{a}(\mathrm{~Pa} \mathrm{~s})$ & $1.19 \times 10^{-5}$ & [18] \\
\hline Gas viscosity inside cathode domains, $\mu_{a}(\mathrm{~Pa} \mathrm{~s})$ & $2.46 \times 10^{-5}$ & [18] \\
\hline $\begin{array}{l}\text { Anode standard exchange current density, } i_{0 a}(\mathrm{~A} \\
\left.\mathrm{m}^{-2}\right)\end{array}$ & $1 \times 10^{5}$ & $\begin{array}{c}{[22] \text { and }} \\
\text { Optimization }\end{array}$ \\
\hline $\begin{array}{l}\text { Cathode standard exchange current density, } i_{o c}(\mathrm{~A} \\
\left.\mathrm{m}^{-2}\right)\end{array}$ & 1.0 & $\begin{array}{l}{[22] \text { and }} \\
\text { Optimization }\end{array}$ \\
\hline Transfer coefficient, $\alpha_{a, a}, \alpha_{a, c}, \alpha_{c, a}, \alpha_{c, c}$ & $1,1,1.28,0.72$ & $\begin{array}{c}{[16] \text { and }} \\
\text { Optimization }\end{array}$ \\
\hline Tortuosity factor $\tau$ & 1.4 & [22] \\
\hline Cell temperature, $T(\mathrm{~K})$ & 318 & measure data \\
\hline
\end{tabular}
boundary conditions of the model 
Table 1 shows the parameters used in the model. Figure 2a shows the simulation results after optimization based on the experimental data. It can be seen that in the low voltage region (corresponding to high current and low hydrogen concentration), the simulation results are significantly higher than the experimental values, which indicates that the mathematical model does not respond better to the actual electrochemical process in this interval. In the low voltage region, the hydrogen concentration decreases significantly, and the effect of nitrogen on hydrogen should be significantly higher. Since it is very difficult to correct the binary diffusion coefficient of the gas in the mass transfer model. Therefore, equation 3 is modified in this paper by setting the correction factor $\gamma$ for the concentration polarization. the corrected local current density of the anode is as follows.

$$
i_{a}=i_{0, a}\left(e^{\left(\frac{c_{\mathrm{H}_{2}}}{c_{H_{2, n f}}}\right)^{\gamma}} * \exp \left(\frac{\alpha_{a, a} F \eta_{a}}{R T}\right)-\exp \left(\frac{-\alpha_{c, a} F \eta_{a}}{R T}\right)\right)
$$

The correction factor $\gamma=1.65$ obtained by the COMSOL software optimization tool using the experimental data. Figure $2 \mathrm{~b}$ shows the results of the simulation results with the experimental values. It can be seen that the simulation results can match well with the experimental values. Especially near the peak power, the simulation model can predict the experimental results well. And the study in this paper focuses on the region near the peak power, so it can be considered that the model is applicable in this paper.
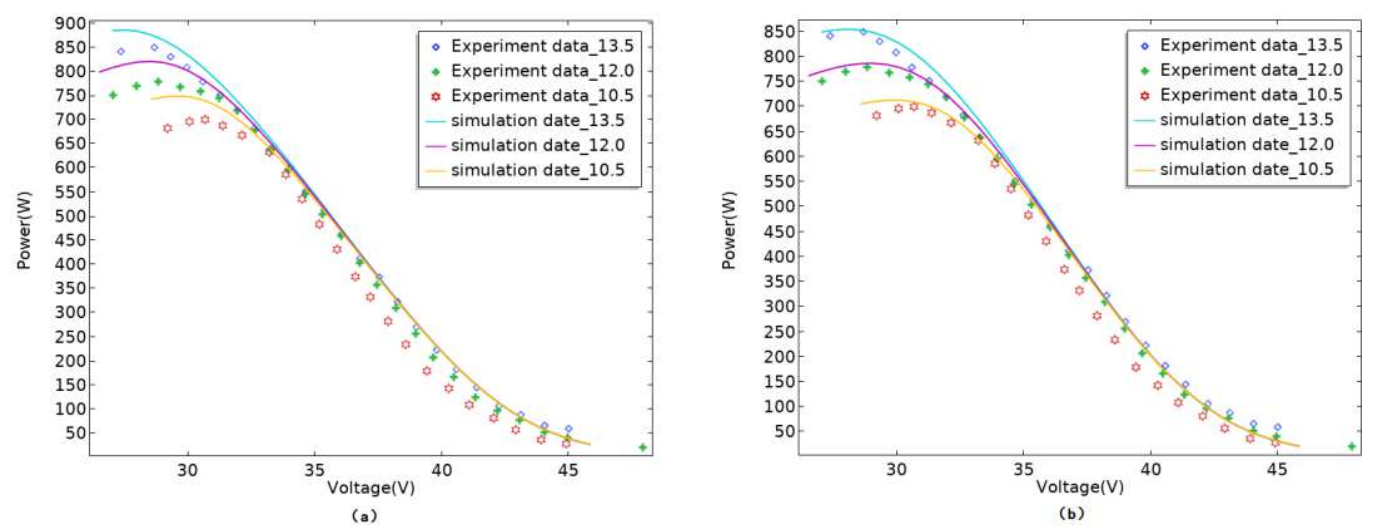

Figure2.a Comparison of simulation results and experiment; Figure2.b Comparison of modified simulation results and experiment

\subsection{Influence of anode channel length on power density}

Figure 3 shows the variation of maximum power of fuel cell with anode channel length for a given boundary conditions (output voltage of single cell is not less than $0.5 \mathrm{~V}$, fuel efficiency is not less than $45 \%$ ). When the length of anode channel is more than $90 \mathrm{~mm}$, the maximum power density changes little with the length of anode channel. When the length of anode channel is less than $90 \mathrm{~mm}$, the maximum power density increases gradually with the decrease of channel length, and the slope of the curve increases gradually. However, the maximum power density when the length is 
$10 \mathrm{~mm}$ is only $2.2 \%$ higher than the maximum power density when the length is 180 mm. Therefore, the anode runner length has little effect on the maximum power density.

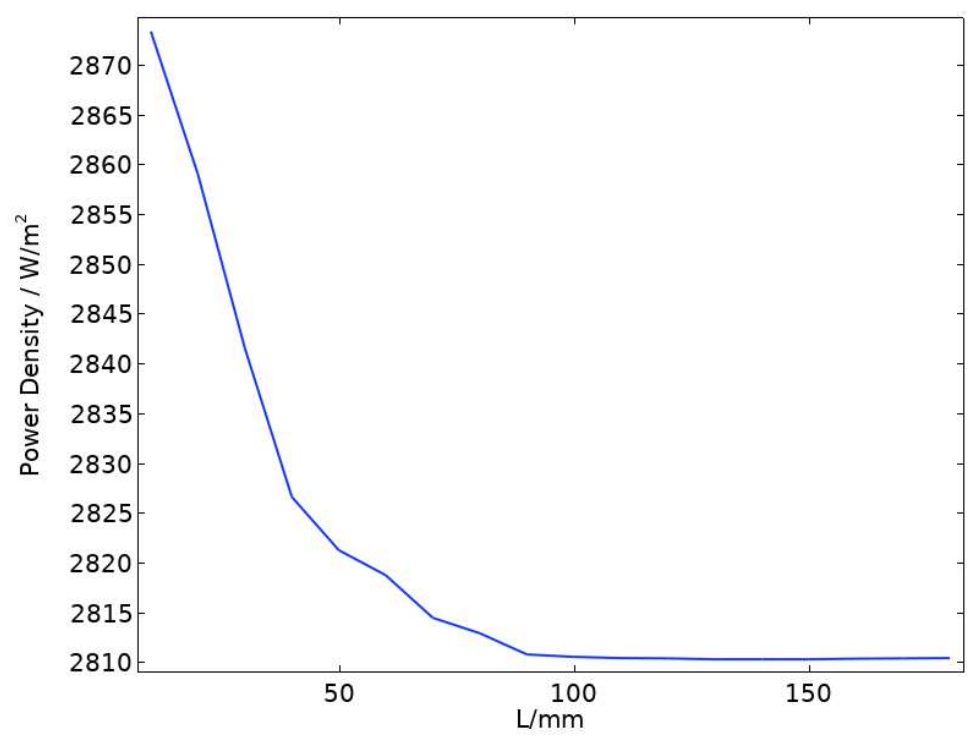

Figure3. Variation of maximum power density with anode channel length

\section{3. influence of anode channel length on hydrogen molar concentration at anode} outlet

The variation trend of hydrogen's molar concentration at anode channel outlet with the channel length is similar to that of power density, as shown in Figure 4. The high molar concentration of hydrogen at the outlet of the anode channel indicates that the proportion of hydrogen participating in the electrochemical reaction is reduced, and the energy of hydrogen participating in the electrochemical reaction is converted into more electric energy, thus reducing the heat release during the electrochemical reaction. This is beneficial to the thermal management of the fuel cell. Also the higher molar concentration of hydrogen makes the exhaust waste heat utilization of the fuel cell more valuable. However, the molar concentration of hydrogen at a length of 10 $\mathrm{mm}$ is only $4.5 \%$ higher than that at a length of $180 \mathrm{~mm}$. Therefore, the anode runner length also has little effect on the exit hydrogen molar concentration. 


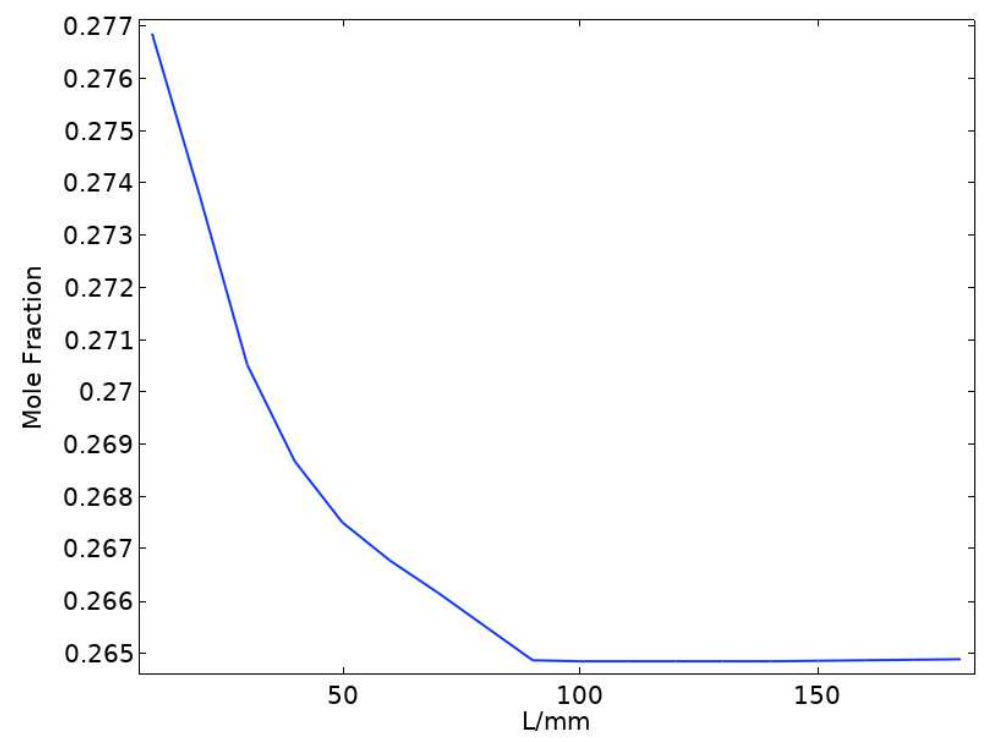

Figure4. Variation of hydrogen molar concentration at anode outlet with anode channel length

\section{4. influence of anode channel length on current density}

Figure 5 shows the variation of current density along the anode channel for different anode channel lengths. It can be seen from the figure that the current density at the entrance of the channel is the same, and there is a small increase in the current density at the exit as the anode channel length decreases, but the gradient of the current density increases sharply, which is a detrimental effect on the operation of the fuel cell, so the length of the anode channel length should not be too short.

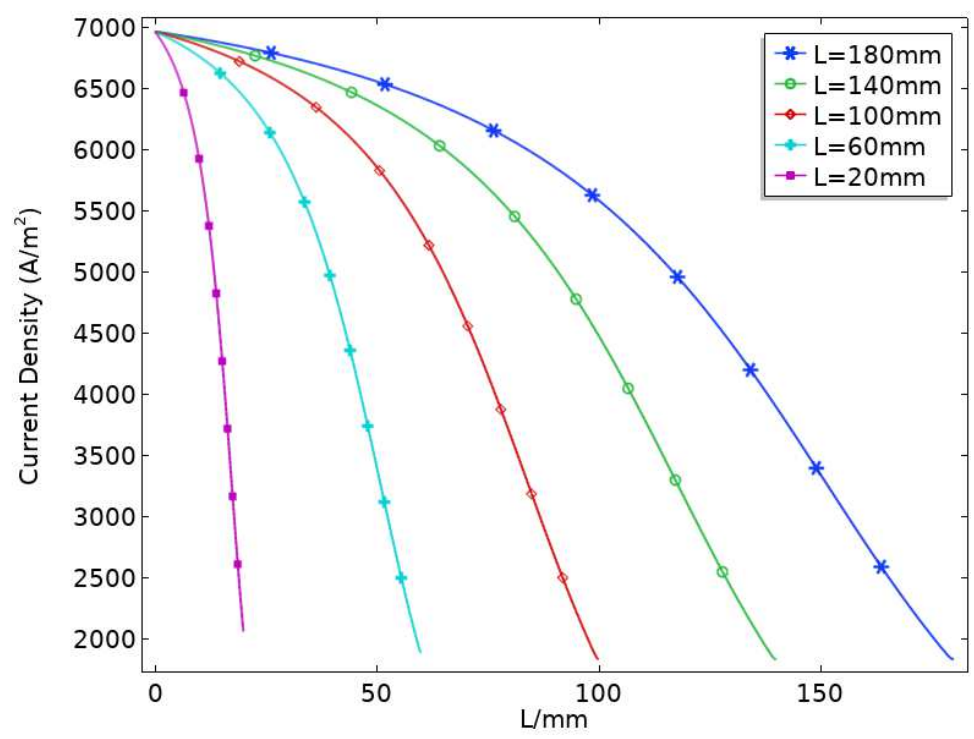

Figure5. Variation of current density with anode channel length

\section{5. influence of anode channel length on the fuel's flow resistance}

From Figure 6, it can be seen that the resistance loss of fuel flow is linearly 
proportional to the length of the anode channel, and the dashed line represents the average flow velocity of fuel in the channel, which is also linearly proportional to the length of the anode channel. However, comparing the slope of the two curves, the rising speed of pressure loss is less than that of velocity. At the same time, the fuel resistance loss of $180 \mathrm{~mm}$ length is 14 times of that of $10 \mathrm{~mm}$ length. Therefore, the length of anode channel has a great influence on the flow resistance loss of fuel.

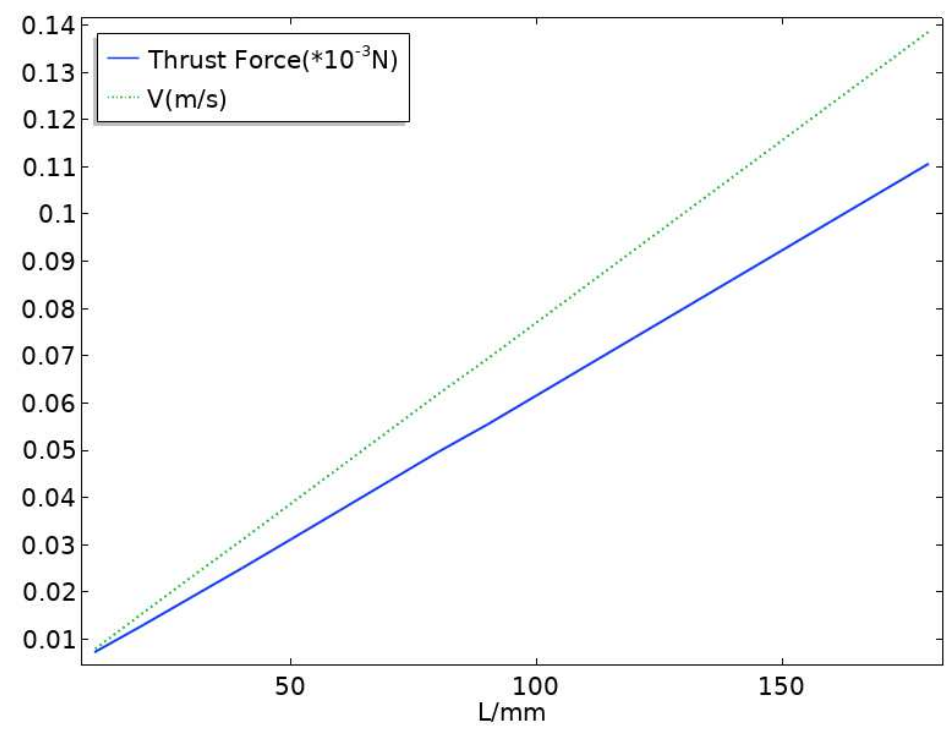

Figure6. Variation of fuel flow velocity and flow resistance with anode channel length

\section{Conclusion}

In this paper, a two-dimensional simulation model of PEMFC fueled with ammonia reforming gas is established, and the concentration-dependent electrochemical reaction model is suitably modified according to the experimental results by adding a correction factor for the concentration difference polarization, and the correction factor $\gamma=1.65$ is obtained by an optimization algorithm. Next, the influence of anode channel length on the characteristics of fuel cell was further studied. The results show that the length of the anode channel has little effect on the maximum power density and the molar concentration of residual hydrogen at the outlet of the fuel cell, but has a greater impact on the current density and the flow resistance of the fuel. Increasing the length of the anode channel can make the current density more uniform, but will increase the flow resistance of the fuel. Therefore, a compromise should be considered in the geometric optimization of the fuel cell.

\section{Declarations}

Ethics approval and consent to participate

Not applicable

Consent for publication 
Not applicable

\section{Availability of data and materials}

The datasets during and/or analysed during the current study available from the corresponding author on reasonable request.All data generated or analysed during this study are included in this published article.

\section{Competing interests}

The authors declare that they have no competing interests.

\section{Funding}

No funding

\section{Authors' contributions}

Jianfeng Zhao conducts simulation and finished the manuscript, Yifan Liang conducts experiments, All authors have read and approved the final manuscript.

\section{Acknowledgements}

The authors wish to thank the reviewers for their careful, unbiased, and constructive suggestions, which led to this revised manuscript.

\section{References}

[1] Cano, Z. P. , Banham, D., Ye, S. , Hintennach, A. , Lu, J. , \& Fowler, M. , et al.(2018) Batteries and fuel cells for emerging electric vehicle markets. Nature Energy, 3(4):279-289.https ://doi.org/10.1038/s41560-018-0108-1

[2] Khzouz, M. , Gkanas, E. I. , Jia, S. , Sher, F. , \& Qubeissi, M. A. . (2020). Life cycle costing analysis: tools and applications for determining hydrogen production cost for fuel cell vehicle technology. Energies, 13(15), 3783. https ://doi.org/ 10.3390/en13153783

[3] Moradi, R. , \& Groth, K. M. . (2019). Hydrogen storage and delivery: review of the state of the art technologies and risk and reliability analysis. International Journal of Hydrogen Energy, 44(23), 12254-12269. https ://doi.org/ 10.1016/j.ijhydene.2019.03.041

[4] Sajjan, P. , Nayak, V. , Padaki, M. , Zadorozhnyy, V. Y. , \& Konik, P. A. . (2020). Fabrication of cellulose acetate film by blending technique with palladium acetate for hydrogen gas separation. Energy \& Fuels,,34, 11699-11707.https ://doi.org/

10.1021/acs.energyfuels.0c02030

[5] Alkali, A. . (2020). Electroless plating of palladium membranes on porous substrates for hydrogen separation and the effects of process factors on plating rate and efficiency: a review. Journal of Power and Energy Engineering, 08(2), 1-19.https ://doi.org/ 10.4236/jpee.2020.82001 [6] Kamakshi, R Kumar, Saraswat, V. K. , Kumar, M. , \& Awasthi, K. . (2019). Active block copolymer layer on carboxyl-functionalized pet film for hydrogen separation. International Journal of Hydrogen Energy, 45(37) :18676-18684.https ://doi.org/ 10.1016/j.ijhydene.2019.07.174

[7] Hunter, H. , Makepeace, J. W. ， Wood, T. J. , Mylius, O. S. , Kibble, M. G. , \& Nutter, J. B. , et al. (2016). Demonstrating hydrogen production from ammonia using lithium imide powering a small proton exchange membrane fuel cell. Journal of Power Sources, 329 , 138-147.https ://doi.org/ 10.1016/j.jpowsour.2016.08.004

[8] Ikaheimo, J. , Kiviluoma, J. , Weiss, R. , \& Holttinen, H. . (2018). Power-to-ammonia in future north european $100 \%$ renewable power and heat system. International Journal of Hydrogen 
Energy, 43(36), 17295-17308.https ://doi.org/ 10.1016/j.ijhydene.2018.06.121

[9] Badescu, V. . (2020). Optimal design and operation of ammonia decomposition reactors. International Journal of Energy Research, 44(4) : 5360-5384.https ://doi.org/ 10.1002/er.5286 [10] Aiyejina, A. , \& Sastry, M. . (2012). Pemfc flow channel geometry optimization: a review. Journal of Fuel Cell Science \& Technology, 9(1), 011011.https ://doi.org/ 10.1115/1.4005393 [11] Yang, C. , Wan, Z., X Chen, X Kong, \& X Wang. (2020). Geometry optimization of a novel $\mathrm{m}$-like flow field in a proton exchange membrane fuel cell. Energy Conversion and Management, 228(9), 113651.https ://doi.org/ 10.1016/j.enconman.2020.113651 [12] Chen, W. H. , Tsai, Z. L. , Chang, M. H. , You, S. , \& Kuo, P. C. . (2021). Geometry optimization and pressure analysis of a proton exchange membrane fuel cell stack. International Journal of Hydrogen Energy(1).https ://doi.org/ 10.1016/j.ijhydene.2021.01.222

[13] Grigoriev, S. A. , Kalinnikov, A. A. , Kuleshov, N. V. , \& Millet, P. . (2013). Numerical optimization of bipolar plates and gas diffusion electrodes for pbi-based pem fuel cells. International Journal of Hydrogen Energy, 38(20), 8557-8567.https ://doi.org/ 10.1016/j.ijhydene.2012.12.021

[14] Liu, Chen, Xie. (2020). A two-dimensional analytical model of PEMFC with dead-ended anode[J]. International Journal of Green Energy, 17(4):255-273.https ://doi.org/

10.1080/15435075.2020.1722133

[15] Ahmadi, N. , A D advand, Mirzaei, I. , \& Rezazadeh, S. . (2018). Modeling of polymer electrolyte membrane fuel cell with circular and elliptical cross-section gas channels: a novel procedure. International Journal of Energy Research, 42(8):2805-2822.https ://doi.org/ 10.1002/er.4069

[16] Liu, J. X. , Guo, H. , Ye, F. , \& Ma, C. F. . (2017). Two-dimensional analytical model of a proton exchange membrane fuel cell. Energy, 119(JAN.15), 299-308.https ://doi.org/ 10.1016/j.energy.2016.12.075

[17] Tsai, S. W. , \& Chen, Y. S. . (2017). A mathematical model to study the energy efficiency of a proton exchange membrane fuel cell with a dead-ended anode. Applied Energy, 188, 151-159. https ://doi.org/ 10.1016/j.apenergy.2016.11.128

[18] Wang, B. , Wu, K. , Yang, Z. , \& Jiao, K. . (2018). A quasi-2d transient model of proton exchange membrane fuel cell with anode recirculation. Energy Conversion \& Management,

171(PT.1083-186), 1463-1475.https ://doi.org/ 10.1016/j.enconman.2018.06.091

[19] Yesilyurt, S. , Siegel, J. B. , \& Stefanopoulou, A. G. . (2012). Modeling and experiments of voltage transients of polymer electrolyte membrane fuel cells with the dead-ended anode.

Journal of Fuel Cell Science \& Technology, 9(2), 021012. https ://doi.org/ 10.1115/1.4005626 [20] Le Bars, M. , \& Worster, M. G. . (2006). Interfacial conditions between a pure fluid and a porous medium: implications for binary alloy solidification. Journal of Fluid Mechanics, 550(-1), 149-173.https ://doi.org/ 10.1017/S0022112005007998

[21] Kee R J , Coltrin M E , Glarborg P, et al. Chemically Reacting Flow: Theory, Modeling, and Simulation[M]. Wiley ,2017:91-149.

[22] Ubong, E. U. , Shi, Z. , \& Wang, X. . (2008). A-3d-modeling and experimental validation of a high temperature pbi based pemfc. ECS Transactions, 16, 79-90.https ://doi.org/

10.1149/1.2981845 